\title{
The Fibrosis-Cirrhosis Index (FCI) for Staging of Liver Fibrosis in Chronic Hepatitis C
}

\author{
Yehia S.Younis ${ }^{1,}$ Hosam A.Baiomy ${ }^{1, I b r a h i m ~ M . E l-S h a w a f ~}{ }^{2,}$ Ebada M. Said ${ }^{1}$, \\ Amr I.I. Eisa ${ }^{3}$ \\ ${ }^{1}$ Hepatology, Gastroenterology and Infectious Diseases Department, Faculty of Medicine, \\ Benha University,Benha, Egypt. \\ 2 Pathology Department, Faculty of Medicine, Mansoura University, Mansoura,Egypt. \\ ${ }^{3}$ Hepatology, Gastroenterology and Infectious Diseases Department, Mansoura Health Insurance \\ Hospital, Manosura,,Egypt.
}

Corresponding Author Amr Ibrahim Ibrahim Eisa

Mobile: $+201001904008$

E mail:
Dr.amr3esa@yahoo.co
$m$

Key words: liver fibrosis, liver biopsy, The FibrosisCirrhosis Index (FCI).
Background and study aim : Chronic hepatitis $\mathrm{C}(\mathrm{CHC})$ is a major global health problem with its consequences of liver fibrosis and cirrhosis. Liver fibrosis is the main predictor of the progression of chronic hepatitis $\mathrm{C}$, and its assessment can help determine therapy. Several indices are available to predict cirrhosis. The fibrosis - cirrhosis index (FCI) was proposed to be efficient for none invasive staging of liver fibrosis besides being simple and inexpensive. This study is designed to assess the accuracy of the fibrosiscirrhosis index (FCI) for non-invasive staging of liver fibrosis in patients with chronic hepatitis $\mathrm{C}$ compared to the liver biopsy findings.

Patients and methods: This study was conducted on 150 chronic hepatitis C

\section{INTRODUCTION}

Chronic hepatitis $\mathrm{C}(\mathrm{CHC})$ is a major global health problem with its consequences of liver fibrosis and cirrhosis up to hepatocellular carcinoma [1].

In Egypt, Being a developing country, CHC represents a real medical and financial problem as it affects about $14.7 \%$ of the Egyptian population making it one of the countries with highest prevalence worldwide [2].

Liver fibrosis is the main predictor of the progression of $\mathrm{CHC}$, and its assessment can help determine therapy [3].

Liver biopsy is still considered the gold standard for staging fibrosis, however it is invasive, expensive and patients who attended the Hepatology, Gastroenterology and Infectious Diseases Department at Benha University Hospital and El Mansoura Health-Insurance Hospital. Another group of 30 healthy subjects (with negative hepatitis viral markers) represented the control group.

Results: FCI was a relatively sensitive, specific and accurate marker of fibrosis. At a cutoff value of $<0.12$, FCI had a NPV of $81.7 \%$ for the exclusion of significant fibrosis, while at cutoff value $>0.19$ it had a PPV of $82.5 \%$ for the diagnosis of advanced fibrosis.

Conclusion: FCI is a simple index that integrates ALP, bilirubin, albumin and platelet count for staging fibrosis from absent up to cirrhosis.

not suitable for all patients who may get severe side effects that may lead to death [4]. There is a need for a simple, safe, noninvasive and inexpensive test to assess fibrosis and cirrhosis [5].

Several indices are available to predict cirrhosis but no method or score is available on exclusive basis to diagnose earlier fibrosis stages [6].

Several scoring systems like AST to ALT ratio (AAR), AST-Platelet ratio (APRI), Fibrotest (FT), Fibrosis Index (FI) and FIB-4 with different thresholds to predict presence or absence of fibrosis or cirrhosis in patients infected with $\mathrm{HCV}$ had been proposed. However, mild fibrosis (F0) to end stage cirrhosis cannot be predicted accurately using a single system [7]. 
The fibrosis-cirrhosis index (FCI) was proposed and comprised serum alkaline phosphatase (ALP), bilirubin, albumin and platelet count, where FCI $=[($ ALP $\times$ Bilirubin $) /($ Albumin $\times$ Platelet count $)]$. It was supposed to be efficient for none invasive staging of liver fibrosis besides being simple and inexpensive [8].

\section{PATIENTS AND METHODS}

Study design: Cross-sectional study.

\section{This study:}

Was carried out on 150 patients with evidence of $\mathrm{CHC}$ (positive HCV-Ab and HCV-RNA- PCR with elevated ALT level for more than 6 months). They were 94 males $(62.7 \%)$ and 56 females (37.3\%), and their ages ranged between 18 and 60 years.

All cases were selected from the department of Hepatology, Gastroenterology and Infectious Diseases, Benha University Hospitals, and Mansoura Health Insurance Hospital, within the period between October 2013 to October 2014.

The criteria for exclusion were; any contraindication to percutaneous liver biopsy, hepatitis with causes other than $\mathrm{HCV}$, age under 18 years, severe systemic illness and pregnancy.

Patients were sex and age matched with 30 healthy subjects who were volunteer blood donors visiting Benha University Hospitals-blood bank within the same period of the study and who were having normal liver profile with absence of $\mathrm{HCV}-\mathrm{Ab}$, $\mathrm{HBsAg}$ and $\mathrm{HBc} \mathrm{Ab}$ (total) in their sera.

\section{Patients were subjected to the following:}

Full history taking, thorough clinical examination.

Routine laboratory investigations, that included: Complete blood picture. Liver profile tests: prothrombin time and concentration, serum albumin, AST, ALT, Alkaline phosphatase, $\gamma$-GT and serum bilirubin (total and conjugated). Hepatitis viral markers; that included: Detection of HCV-Ab by ELISA technique using Biochem Kit., Detection of HCV-RNA-PCR. Detection of HBsAg by ELISA technique using Sorin Biomedic Kit (for exclusion of + ve cases).

\section{Abdominal Ultrasonography.}

Scoring of king's score: Age (years) x AST (IU/L) x INR/platelet count (109/L)[9], Age-platelet index $(\mathrm{API})=$ Age $($ year $) / \mathrm{PLT}\left(\times 10^{9} / \mathrm{L}\right)[10], \quad$ AST to platelet ratio index (APRI): [(AST of the sample/ reference AST)x100]/ platelets count $\left(10^{9} / \mathrm{L}\right)$ $[11]$, FIB-4 score $=[$ age $($ years $)] \times$ AST $(U / L)] /$ [number of platelets $\left.\left(10^{9} / \mathrm{L}\right)\right] \times$ ALT $(\mathrm{U} / \mathrm{L}){ }^{1 / 2}$ ] [12], FCI $=($ ALP $\times$ bilirubin $) /($ albumin $\times$ platelet count) [8].

Liver biopsy and histopathological examination for necro Inflammatory grading and fibrosis staging applying the METAVIR scoring system $[13,14]$.

Samples collection, preparation and handling: A sample of 8-10 ml of venous blood was withdrawn under aseptic condition. One $\mathrm{ml}$ of blood was added to an anticoagulant- (EDTA) containing tube for complete blood count. The rest of the blood sample was left to clot in a sterile, clean and dry tube. After clotting, samples were thoroughly separated from all cellular material by centrifugation. Multiple freeze-thaw procedures were avoided. Any precipitates in specimens were removed by centrifugation before testing, and specimens with obvious hemolysis were excluded.

\section{Abdominal Ultrasonography:}

Liver was assessed for: size (span), echogenicity, surface, thickening of portal tracts, portal vein diameter, hepatic veins, inferior vena cava and presence or absence of focal lesions.

Spleen was assessed for: size, echogenicity, splenic vein diameter and presence or absence of collaterals. Other data concerning the gall bladder, both kidneys, pancreas, para aortic region as well as detection of ascites all were fulfilled.

\section{Biopsy of the liver:}

N.B: Patients with ascites were excluded from this study.

\section{Histopathological examination:}

The stained sections were examined for: Evidence of etiology: HCV, Schistosomiasis. Assessment of necro inflammatory grading and fibrosis staging applying the METAVIR scoring system of [15]. Where Activity was graded according to the intensity of necro inflammatory lesions: $\mathrm{A} 0=\mathrm{no}$ histological activity, $\mathrm{A} 1=$ mild activity, $\mathrm{A} 2=$ moderate activity, A3=severe activity. The stage of fibrosis $(\mathrm{F})$ was assessed on a five Point scale: $\mathrm{F} 0=$ no fibrosis, $\mathrm{F} 1=$ Portal fibrosis without septa, F2=Few septa, F3=numerous septa without cirrhosis, F4=cirrhosis.

\section{Statistical Analysis}

Data were tabulated, coded then analyzed using the computer program SPSS (Statistical package for social science) version 17.0to obtain 
Descriptive statistics were calculated in the form of: A- Mean \pm Standard deviation (SD) for quantitative parametric data. B- Median and range (Minimum-maximum) for quantitative nonparametric data. C- Frequency (Number-percent) for qualitative data.

\section{Analytical statistics:}

In the statistical comparison between the different groups, the significance of difference was tested using one of the following tests:-

A-Student's $t$-test:-Used to compare between mean of two groups of numerical (parametric) data. BMann Whitney U test: Used to compare between two groups of numerical (non-parametric) data. C- Kruskal Wallis test: Used to compare between more than two groups of numerical (non-parametric) data followed by MannWhitney for multiple comparisons.

The sensitivity and specificity of FCI, FIB4, King's score, APRI and API to differentiate between F0$\mathrm{F} 1$ and F2-F4 and also between F0-F2 and F3-F4 fibrosis grades were examined at different cutoff points using ROC curve analysis to determine the best cutoff point as well as the diagnostic power of each test. A $P$ - value $<0.05$ was considered statistically significant in all analyses.

\section{RESULTS}

The study was conducted on 150 patients (cases group) $\{94$ males $(62.7 \%), 56$ females $(37.3 \%)\}$. The (control group) 30 subjects $\{22$ males (73.3 $\%), 8$ females $(26.7 \%)\}$ (Figure 1).

There is a statistically significant difference between cases and control groups (p 0.05) as regards platelets, ALT, AST, ALP, APRI, FCI, FIB4, king's score, and API. Cases group had significantly lower platelets count, higher ALT, AST, ALP levels and higher APRI, FCI, FIB4, king's score and API values (Table 1).

Albumin, INR, Bilirubin, AST, ALP, APRI, FCI, King's score, API \& FIB4 where significantly lower, while platelets were significantly higher in patients with METAVIR $(\mathrm{F} \leq 1)$ compared to those with METAVIR $(F \geq 2)(P<0.001)$ (Table 3$)$.

Albumin, INR, Bilirubin, AST, ALP, APRI, FCI, King's score, API \& FIB4 were significantly lower, while platelets were significantly higher in patients with METAVIR $(\mathrm{F} \leq 2)$ compared to those with METAVIR $(\mathrm{F} \geq 3)(\mathrm{P}<0.001)$. (Table 4).
As shown in table (5) and figure (20):

- ROC curves of biomarkers for discriminating $\mathrm{CHC}$ patients with no or minimal liver fibrosis $(\mathrm{F} \leq 1)$ by METAVIR score from those with significant liver fibrosis $(\mathrm{F} \geq 2)$.

- Using cutoff values ( $0.705-0.125-1.445$ $13.06-2.5)$ the areas under the curve (AURC) were $(0.79-0.90-0.89-0.86$ and 0.77) for APRI, FCI , FIB4, King's score and API respectively . sensitivity and specificity of FCI and FIB4 $(87.6 \%, 83.1 \%$ - $86.5 \%, 81.7 \%$ ) were higher than King's score, APRI and API (81.6 \% ,79.7 \% - 74.2 , $70.0 \%$ and $77.8 \%, 56.7$ respectively) in discriminating patients with $(\mathrm{F} \leq 2)$ from those with $(\mathrm{F} \geq 2)$. PPV of FCI and FIB4 $(88.6 \%$ and $87.5 \%)$ was $>$ King's score $(85.5 \%)>$ APRI $(78.6 \%)>$ API $(72.9 \%)$. NPV of FCI and FIB4 $(81.7 \%$ and 80.3$)$ was $>$ King's score $(74.6 \%)>$ APRI $(72.3 \%)>$ API $(69.3 \%)$. The accuracy of FCI $(85.6 \%)$ was $>$ FIB4 $(84.6$ $\%)>$ King's score $(80.8 \%)>$ APRI $(72.3 \%)$ $>$ API $(69.3 \%)$. Out of assessed fibrosis biomarkers, FCI was the most accurate one for discrimination of significant fibrosis $(\mathrm{F} \geq 2)$. At a cut off value 0.12 it was $87.6 \%$ sensitive \&86.5\% specific with AUROC= 0.90 .

As shown in table (6) and figure (21):

- ROC Curves of biomarkers for discriminating $\mathrm{CHC}$ patients with $(\mathrm{F} \leq 2)$ liver fibrosis from those with advanced liver fibrosis $(\mathrm{F} \geq 3)$.

Using cutoff values $(0.195-2.115-15.06-$ 0.975 and 3.5) the areas under the curve (AURC) were (0.91-0.87-0.89-0.85 and 0.79) for FCI, FIB4, King's score, APRI and API respectively. Increase sensitivity and specificity of FCI and FIB4 $(88.1 \%, 87.6 \%$ and $83.05 \%, 80 \%)$ compared with King's score, APRI and API $(86.2 \%, 72.7 \%-74.6 \%, 76.7 \%$ and $78.3 \%, 72.7 \%)$ respectively. PPV of FCI $(82.5 \%)$ was $>$ FIB4 $(73.1 \%)>$ APRI $(67.7 \%)>$ King's score $(67.6 \%)$ $>$ API $(65.3 \%)$. NPV of FCI $(91.8 \%)>$ King's score $(88.9 \%)>$ FIB4 $(87.8 \%)>$ API $(83.3 \%)>$ APRI $(82.1 \%)$. The accuracy of FCI $(87.8 \%)$, FIB4 (81.8\%), King's score (78.1\%), APRI (75.8 $\%$, API $(74.7 \%)$. Out of assessed fibrosis biomarkers, FCI was the most accurate one for discrimination of advanced fibrosis $(\mathrm{F} \geq 3)$. At a cut off value 0.19 it was $88.1 \%$ sensitive \& $87.6 \%$ specific with AUROC $=0.91$. 


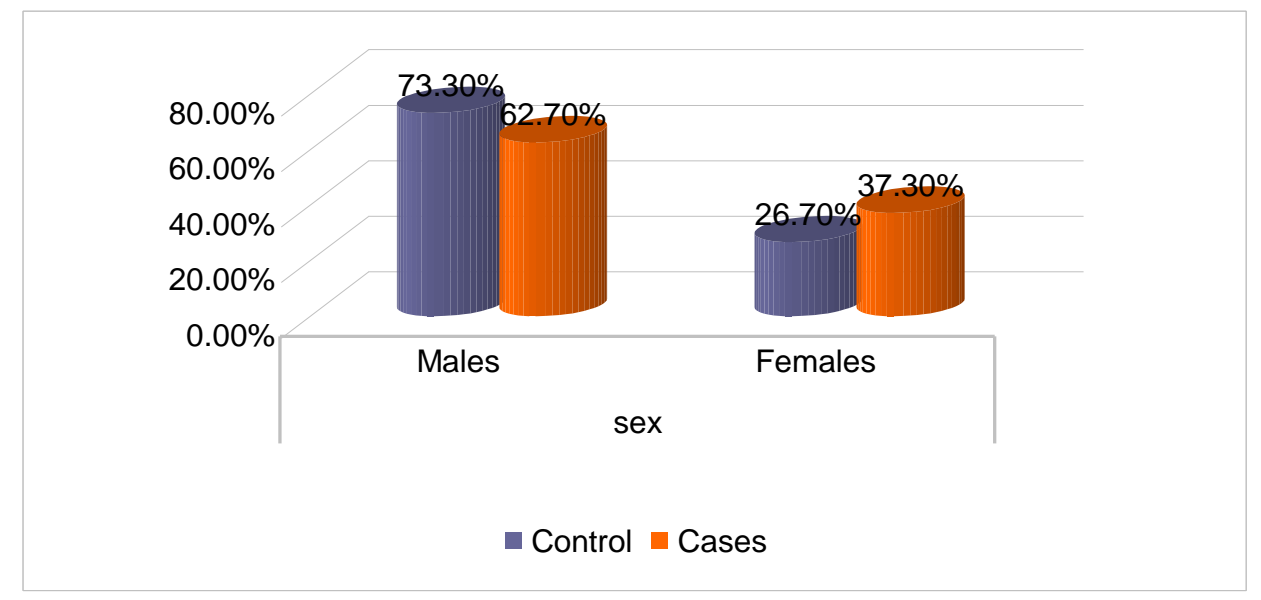

Figure (1): Gender of the studied groups within the study

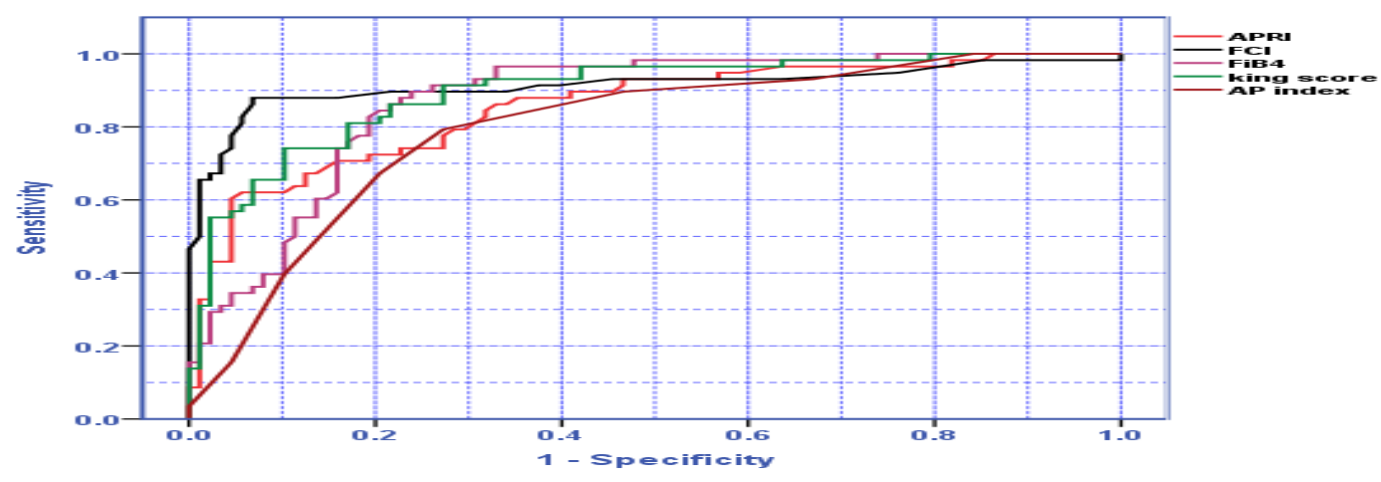

Figure (2): ROC1: Differentiation between $(\mathrm{F} \leq 1)$ and ( $\mathrm{F} \geq 2)$ using different fibrosis biomarkers.

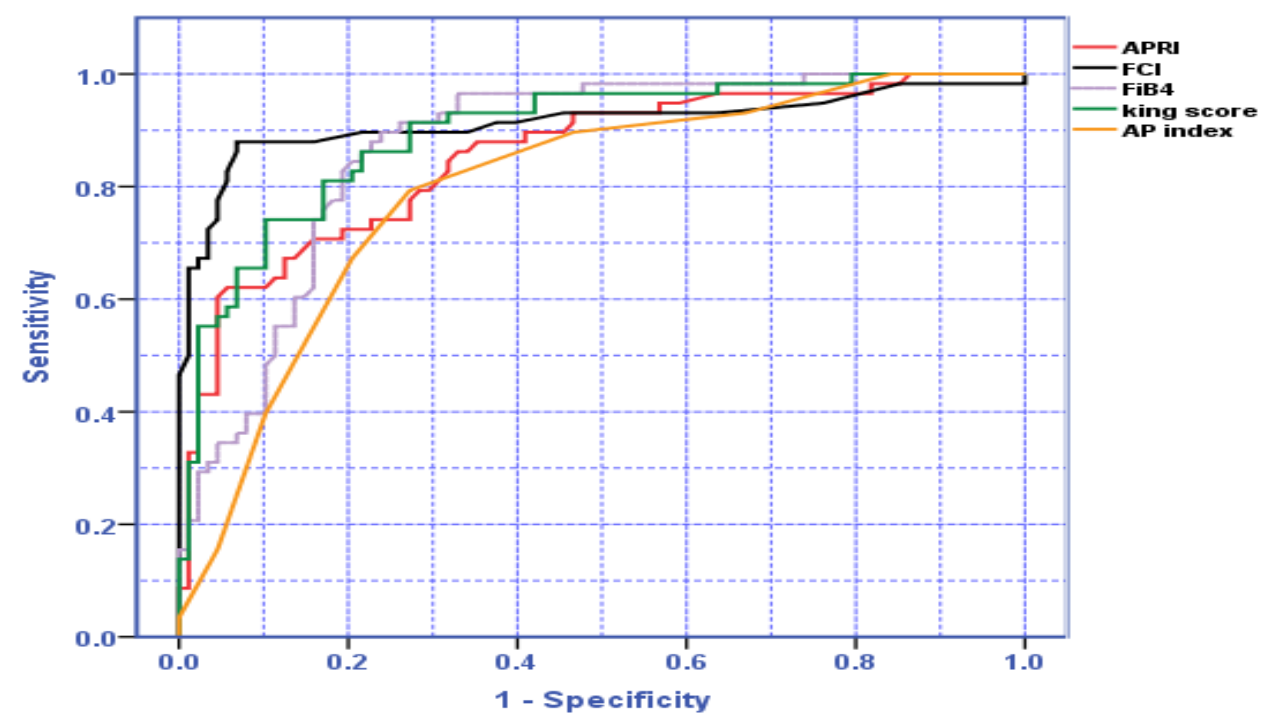

Figure (3): ROC2: Differentiation between ( $\mathbf{2}$ 2) and (F $\geq 3$ ) using different fibrosis biomarkers. 
Table (1): Laboratory findings of the studied cases and control groups.

\begin{tabular}{|l|c|c|c|c|}
\hline & Cases & Control & Test used & P \\
\hline HB(gm/dl) & $13(11-13.8)$ & $13.5(11.3-15.5)$ & Mann-Whitney & 0.9 \\
\hline WBCsx10 $\left(/ \mathrm{mm}^{3}\right)$ & $6.2(4.2-11.9)$ & $6(3.611 .9)$ & Mann-Whitney & 0.9 \\
\hline Plateletsx10 $(/ \mathrm{mm} 3)$ & $158.87 \pm 44.66$ & $340.83 \pm 47.64$ & Unpaired -test & $<0.001$ \\
\hline Albumin(g/l) & $4.2(3.3-4.8)$ & $4.2(3.5-4.9)$ & Mann-Whitney & 0.7 \\
\hline INR & $1.07(0.8-1.7)$ & $1(0.6-1.3)$ & Mann-Whitney & 0.007 \\
\hline Bilirubin(mg/dl) & $0.9(0.5-2)$ & $0.85(0.6-1.1)$ & Mann-Whitney & 0.14 \\
\hline Alk.ph(IU/L) & $131 \pm 56$ & $98 \pm 23$ & Unpaired t-test & $<0.001$ \\
\hline AST(U/L) & $57(7-198)$ & $24(6-40)$ & Mann-Whitney & $<0.001$ \\
\hline ALT(U/L) & $40(12-73)$ & $21(6-40)$ & Mann-Whitney & $<0.001$ \\
\hline AST/ALT & $1.5(0.18-5)$ & $1.15(0.18-6)$ & Mann-Whitney & 0.4 \\
\hline APRI & $0.86(0.06-4.4)$ & $0.15(0.04-0.26)$ & Mann-Whitney & $<0.001$ \\
\hline FCI & $0.17(0.00-1.13)$ & $0.06(0.0-0.1)$ & Mann-Whitney & $<0.001$ \\
\hline FiB4 & $1.86(0.07-22.77)$ & $0.44(0.06-1.11)$ & Mann-Whitney & $<0.001$ \\
\hline King's score & $15.45(0-100.9)$ & $1.6(0.21-2.8)$ & Mann-Whitney & $<0.001$ \\
\hline API & $3(0-8)$ & $0(0-1)$ & Mann-Whitney & $<0.001$ \\
\hline
\end{tabular}

Table (2): Age, Laboratory data and Fibrosis biomarker in patients with different METAVIR fibrosis stages (F0-F4)

\begin{tabular}{|c|c|c|c|c|c|c|c|}
\hline & \multicolumn{5}{|c|}{ METAVIR FIBROSIS STAGE } & \multirow{2}{*}{$\mathbf{P}$} \\
\hline & & F0 & F1 & $\mathrm{F} 2$ & $\mathrm{~F} 3$ & $\mathrm{~F} 4$ & \\
\hline \multirow{2}{*}{ Age (y) } & Median & 25 & $35^{\mathrm{a}}$ & $43^{\mathrm{a}}$ & $45.5^{\mathrm{ab}}$ & $46^{\mathrm{ab}}$ & \multirow[t]{2}{*}{$\overline{<0.001}$} \\
\hline & Range & $18-35$ & $20-56$ & $19-57$ & $27-59$ & $34-56$ & \\
\hline \multirow{2}{*}{$\mathrm{Hb}(\mathrm{mg} / \mathrm{dl})$} & Median & 13.5 & 13.2 & 12.9 & 13 & 13.45 & \multirow[t]{2}{*}{0.2} \\
\hline & Range & $11-13.4$ & $11.5-13.8$ & $11.4-13.8$ & $11.5-14.6$ & $11.8-15.6$ & \\
\hline \multirow{2}{*}{$\operatorname{WBCsx} 10^{3}\left(/ \mathrm{mm}^{3}\right)$} & Median & 6.1 & 6.4 & 6.2 & 5.8 & 5.95 & \multirow[t]{2}{*}{0.88} \\
\hline & Range & $3.6-11$ & $3.6-11.9$ & $3.6-11$ & $3.6-11.9$ & $4-11$ & \\
\hline \multirow{2}{*}{$\begin{array}{l}\begin{array}{l}\text { Plateletsx } 10^{3} \\
\left(/ \mathrm{mm}^{3}\right)\end{array} \\
\end{array}$} & Median & 197.5 & 194.5 & $161^{\mathrm{a}}$ & $134^{\mathrm{abc}}$ & $101^{\mathrm{abcd}}$ & \multirow[t]{2}{*}{$<0.001$} \\
\hline & Range & $167-289$ & $99-250$ & $122-278$ & $100-175$ & $69-164$ & \\
\hline \multirow{2}{*}{ S.albumin $(\mathrm{g} / \mathrm{dl})$} & Median & 4.5 & $4.3^{\mathrm{a}}$ & $4.2^{\mathrm{a}}$ & $3.8^{\mathrm{abc}}$ & $3.6^{\mathrm{abcd}}$ & \multirow[t]{2}{*}{$\overline{<0.001}$} \\
\hline & Range & $4.3-4.6$ & $4.1-4.5$ & $4.0-4.8$ & $3.5-4.2$ & $3.3-3.9$ & \\
\hline \multirow{2}{*}{ INR } & Median & 0.9 & 1 & $1.04^{\mathrm{a}}$ & $1.08^{\mathrm{a}}$ & $1.3^{\mathrm{abcd}}$ & \multirow[t]{2}{*}{$<0.001$} \\
\hline & Range & $0.8-1.1$ & $0.95-1.2$ & $1.0-1.34$ & $1-1.3$ & $1.2-1.7$ & \\
\hline \multirow{2}{*}{ S.bilirubin (mg/dl) } & Median & 0.7 & 0.75 & 0.8 & $1.15^{\mathrm{abc}}$ & $1.7^{\mathrm{abcd}}$ & \multirow[t]{2}{*}{$<0.001$} \\
\hline & Range & $0.6-1$ & $0.5-1.1$ & $0.6-1.3$ & $0.7-1.5$ & $1.2-2$ & \\
\hline \multirow{2}{*}{ Alk.ph (U/L) } & Median & 76 & $114^{\mathrm{a}}$ & $143^{\mathrm{a}}$ & $159^{\mathrm{a}}$ & $165^{\mathrm{ab}}$ & \multirow[t]{2}{*}{$<0.001$} \\
\hline & Range & $38-180$ & $37-287$ & $28-310$ & $52-270$ & $58-200$ & \\
\hline \multirow{2}{*}{ AST (U/L) } & Median & 46 & 40 & 50 & 56 & $89^{\text {abcd }}$ & \multirow[t]{2}{*}{$<0.001$} \\
\hline & Range & $7-145$ & $10-148$ & $12-102$ & $10-198$ & $60-135$ & \\
\hline \multirow{2}{*}{$\operatorname{ALT}(\mathrm{U} / \mathrm{L})$} & Median & 37 & 41 & 40 & 43 & 44 & \multirow[t]{2}{*}{0.07} \\
\hline & Range & $12-55$ & $19-57$ & $19-66$ & $12-64$ & $23-73$ & \\
\hline \multirow{2}{*}{ AST/ALT } & Median & 1.39 & 1.09 & 1.40 & 1.58 & $2.07^{\mathrm{abc}}$ & \multirow[t]{2}{*}{0.001} \\
\hline & Range & $0.18-3.21$ & $0.19-4.11$ & $0.24-4.02$ & $0.18-5.25$ & $1.06-4.17$ & \\
\hline \multirow{2}{*}{$\begin{array}{lll}\text { viral } & \text { load } & (\mathrm{IU} / \mathrm{ml}) \\
\mathrm{X} 10^{3} & & \\
\end{array}$} & Median & 588.5 & 728 & 662.5 & 402 & 325 & \multirow[t]{2}{*}{0.3} \\
\hline & Range & $17.9-2920$ & $17.9-2920$ & $22.4-2290$ & $21.2-2100$ & $18-4880$ & \\
\hline \multirow{2}{*}{ APRI } & Median & 0.47 & 0.53 & 0.69 & 0.95 & $2.06^{\mathrm{abcd}}$ & $<0.001$ \\
\hline & Range & $0.06-1.67$ & $0.1-2.57$ & $0.18-1.69$ & $0.16-4.4$ & $1.1-3.07$ & \\
\hline ECI & Median & 0.06 & $0.11^{\mathrm{a}}$ & $0.18^{\mathrm{ab}}$ & $0.3^{\mathrm{abc}}$ & $0.6^{\mathrm{abcd}}$ & $<0.001$ \\
\hline $\mathrm{FCl}$ & Range & $0.03-0.1$ & $0.03-0.34$ & $0.03-0.47$ & $0.07-0.6$ & $0.0-1.13$ & \\
\hline FIR4 & Median & 0.5 & $1.06^{\mathrm{a}}$ & $1.9^{\mathrm{a}}$ & $2.4^{\mathrm{ab}}$ & $6.1^{\text {abcd }}$ & $<0.001$ \\
\hline FIB4 & Range & $0.07-1.6$ & $0.23-4.8$ & $0.5-9$ & $0.5-3.7$ & $2.6-22.7$ & \\
\hline & Median & 4.2 & 7.8 & $13.8^{\mathrm{a}}$ & $20.7^{\mathrm{ac}}$ & $55.9^{\mathrm{abcd}}$ & $<0.001$ \\
\hline King's score & Range & $0-19.6$ & $1.6-65.5$ & $4.2-34.3$ & $3.6-54.3$ & $28.6-100.9$ & \\
\hline$\Delta \mathrm{PI}$ & Median & 2.0 & 3.0 & $3.0^{\mathrm{a}}$ & $5.0^{\mathrm{ac}}$ & $6.0^{\mathrm{abcd}}$ & $<0.001$ \\
\hline AP1 & Range & $0-4$ & $0-7$ & $0-7$ & $1-7$ & $3-8$ & \\
\hline
\end{tabular}

P: Probability Test used: Kruskal-Wallis test followed by Mann-Whitney for multiple comparisons

a: significance relative to F0 group c: significance relative to F2 group

b: significance relative to F1 group d: significance relative to F3 group 
Table (3): Age, Laboratory data and fibrosis biomarkers in patients with $(\mathrm{F} \leq 1)$ METAVIR stages compared to those with $(\mathrm{F} \geq 2)$ stages

\begin{tabular}{|c|c|c|c|c|c|}
\hline & \multicolumn{2}{|c|}{$F \leq 1$} & \multicolumn{2}{|c|}{$\mathbf{F} \geq \mathbf{2}$} & \multirow{2}{*}{$\mathbf{P}$} \\
\hline & Median & Range & Median & Range & \\
\hline Age $(\mathrm{y})$ & 29 & $18-56$ & 45.00 & $19-59$ & $<0.001$ \\
\hline $\mathbf{H b}(\mathrm{gm} / \mathrm{dl})$ & 13.5 & $11-13.8$ & 13 & $11.4-13.8$ & 0.3 \\
\hline WBCs $\times 10^{3}\left(/ \mathrm{mm}^{3}\right)$ & 6.2 & $3.60-11.9$ & 6.2 & $4.0-11.90$ & 0.9 \\
\hline Plateletsx10 ${ }^{3}\left(/ \mathrm{mm}^{3}\right)$ & 195.5 & $99-289$ & 133 & $69-278$ & $<0.001$ \\
\hline S.albumin $(\mathrm{gm} / \mathrm{dl})$ & 4.4 & $4.1-4.6$ & 3.90 & $3.30-4.80$ & $<0.001$ \\
\hline INR & 1 & $0.8-1.5$ & 1.14 & $1-1.7$ & $<0.001$ \\
\hline S.bilirubin $(\mathrm{mg} / \mathrm{dl})$ & 0.7 & $0.5-1.1$ & 1.20 & $0.6-2$ & $<0.001$ \\
\hline Alk.ph (IU/l) & 88 & $37-287$ & 158 & $28-310$ & $<0.001$ \\
\hline$\overline{\mathbf{A S T}(\mathrm{U} / \mathrm{L})}$ & 43 & $7-148$ & 68 & $10-198$ & $<0.001$ \\
\hline ALT (U/L) & 38 & $12-57$ & 42 & $12-73$ & 0.02 \\
\hline AST/ALT & 1.2 & $0.18-4.11$ & 1.67 & $0.18-5.25$ & 0.005 \\
\hline HCV-RNA viral load $(\mathrm{IU} / \mathrm{ml}) \times 10^{3}$ & 728 & $17.9-2920$ & 402 & $18-4880$ & 0.2 \\
\hline APRI & 0.49 & $0.06-2.57$ & 1.2 & $0.16-4.4$ & 0.02 \\
\hline FCI & 0.07 & $0.03-0.34$ & 0.31 & $0-1.13$ & $<0.001$ \\
\hline FIB4 & 0.75 & $0.07-4.8$ & 2.8 & $0.5-22.7$ & $<0.001$ \\
\hline King's score & 7.18 & $0-65.5$ & 23.11 & $3.6-100.9$ & $<0.001$ \\
\hline API & 2 & $0-7$ & 5 & $0-8$ & $<0.001$ \\
\hline
\end{tabular}

Table (4): Age, Laboratory data and fibrosis biomarkers in patients with $(\mathrm{F} \leq 2)$ METAVIR stages compared to those with $(\mathrm{F} \geq 3)$ stages.

\begin{tabular}{|l|c|c|c|c|c|}
\hline & \multicolumn{2}{|c|}{ METAVIR (F $\leq$ 2) stages } & \multicolumn{2}{c|}{ METAVIR (F $\geq 3$ 3) stages } & \multirow{2}{*}{ P } \\
\cline { 2 - 5 } & Median & Range & Median & Range & \\
\hline Age (y) & 32.5 & $18-57$ & 46 & $27-59$ & $<0.001$ \\
\hline $\mathrm{Hb}(\mathrm{gm} / \mathrm{dl})$ & 13.00 & $11-138$ & 13 & $11.5-15.6$ & 0.8 \\
\hline $\mathrm{WBCsX10}$ (/mm) & 6.2 & $4.05-11.9$ & 5.8 & $4-11.9$ & 0.7 \\
\hline PlateletsX103(/mm) & 185.5 & $99-289$ & 116 & $69-175$ & $<0.001$ \\
\hline S.albumin (gm/dl) & 4.4 & $4-4.8$ & 3.7 & $3.3-4.2$ & $<0.001$ \\
\hline INR & 1 & $0.8-1.5$ & 1.2 & $1-1.7$ & $<0.001$ \\
\hline S.bilirubin (mg/dl) & 0.8 & $0.50-1.3$ & 1.4 & $0.7-2$ & $<0.001$ \\
\hline Alk.ph (IU/l) & 105.5 & $28-310$ & 161 & $52-270$ & $<0.001$ \\
\hline AST (U/l) & 46 & $7-148$ & 79 & $10-198$ & $<0.001$ \\
\hline ALT (U/l) & 39.3 & $12.7-65.9$ & 43.6 & $12.3-73.2$ & 0.02 \\
\hline AST/ALT & 1.25 & $0.18-4.11$ & 1.79 & $0.18-5.25$ & 0.001 \\
\hline $\begin{array}{l}\text { HCV-RNA viral load (IU/ml) } \\
\text { x10 }\end{array}$ & 728 & $17.9-2920$ & 325 & $18-4880$ & 0.06 \\
\hline APRI & 0.59 & $0.06-2.57$ & 1.5 & $0.16-4.4$ & $<0.001$ \\
\hline FCI & 0.1 & $0.03-0.47$ & 0.45 & $0-1.13$ & $<0.001$ \\
\hline FIB4 & 1.08 & $0.07-9$ & 3.21 & $0.57-22.77$ & $<0.001$ \\
\hline king score & 9.66 & $0.0-65.53$ & 36.49 & $3.63-100.9$ & $<0.001$ \\
\hline API & 2 & $0-7$ & 5 & $1-8$ & $<0.001$ \\
\hline
\end{tabular}




\section{DISCUSSION}

Viral hepatitis $\mathrm{C}$ is a major global health burden affecting 180 million people worldwide. The severity of the disease associated with $\mathrm{HCV}$ infection varies between asymptomatic, acute and chronic hepatitis, cirrhosis and HCC [16]. Liver fibrosis is the main predictor of the progression of $\mathrm{CHC}$, and its assessment can help to determine therapy [3]. Liver biopsy is considered the gold standard for staging fibrosis, however it is invasive, expensive, has both intraand inter-observer variability as well as sampling errors and it is not suitable for all patients who may get severe side effects that might lead to death [18]\& [19]. Blood-based biomarkers offer a number of advantages over liver biopsy, including safety, cost-savings and wide spread accessibility [20]. Several scoring systems, like AST to ALT ratio (AAR), AST-Platelet ratio index (APRI), Fibro test (FT), Fibrosis Index (FI) and FIB-4, with different thresholds to predict presence or absence of fibrosis or cirrhosis in patients with $\mathrm{CHC}$ had been proposed. However, mild fibrosis (F0) to end stage cirrhosis cannot be accurately distinguished using a single system [7]. The fibrosis-cirrhosis index (FCI) was proposed comprising serum alkaline phosphatase (ALP), bilirubin, albumin and platelet count, where $\mathrm{FCI}=[(\mathrm{ALP} \times$ Bilirubin $) /($ Albumin $\times$ Platelet count)]. It was supposed to be efficient for none invasive staging of liver fibrosis besides being simple and inexpensive [8].

For all these considerations, the main aim of the present study was to assess the accuracy of the fibrosis-cirrhosis index (FCI) for non-invasive staging of liver fibrosis in patients with $\mathrm{CHC}$, compared to the liver biopsy findings.

In the current study serum bilirubin showed a statistically highly significant $(\mathrm{P}<0.001)$ rise with advancement of stages hepatic fibrosis from F0 to F4 respectively as shown in table (2). This comes in agreement with other studies who reported that serum bilirubin level showed a statistically significant increase with advancement of hepatic fibrosis from F1 to F4 [8,17]. On the other hand, another study reported that Serum total bilirubin did not differ significantly within different fibrosis stages [21].

In the present study the level of serum albumin showed a statistically highly significant decline with advancement of stages of hepatic fibrosis from F0 to F4 as shown in table (2). This comes in agreement with other studies that reported that serum albumin showed a statistically significant decline with advancement of hepatic fibrosis [8]. In the contrary side, this result does not come in agreement with another study which reported a non-significant change in serum albumin level with different stages of fibrosis [17].

In the current study the platelet count showed a statistically highly significant decline with advancement of hepatic fibrosis as shown in table (2). This comes in agreement with other studies that reported a highly significant decline in platelet count with the progression of fibrosis [22]. On the other hand another study reported that differences in platelet count were not significantly affected with the progression of liver fibrosis. This disagreement may be explained by the character of patients included in their study as they had genotype 1 and the small number of their cases with advanced hepatic fibrosis stages compared to the present study [23].

The present study showed that APRI had a statistically significant higher values with advancement of hepatic fibrosis, as shown in table (2). Similar results obtained by study [8].

In the present study, the age-platelet index (API) showed a statistically significant higher values with advancement of hepatic fibrosis, as shown in table (5). These results came in agreement with study which created this index. Reported that there was a significant positive correlation between API and necro-inflammatory activity and stage of fibrosis [24].

In the present study, FIB4 showed a statistically higher significant values with advancement of hepatic fibrosis, as shown in table (2). Similar results were obtained by study which reported that FIB4 was significantly increased with progression of fibrosis stages [8].

In the present study, King's sore showed a statistically significant higher values with advancement of hepatic fibrosis as shown in table (5).

In the present study FCI showed a statistically significant higher values with advancement of hepatic fibrosis $(\mathrm{P}<0.001)$, as shown in table $(2)$.

In the present study, the independent variables for prediction of liver fibrosis were FCI, FIB4, King's score, API and APRI. Using ROC curves to assess and compare the diagnostic accuracy of blood markers as FCI, FIB4, King's score, API and APRI in patients with different stages of 
liver fibrosis. As shown in table (5) and figure (20).

\section{Acknowledgment}

The authors would thank Dr. Amr Ibrahim Eisa and Dr. Ayman Elkholi who helped in conducting this study.

\section{Funding: None.}

Conflicts of interest: None.

Ethical Approval:Approved.

\section{REFERENCES}

1. Ghany MG, Strader DB , Thomas DL . Diagnosis, management, and treatment of hepatitis $\mathrm{C}$ : an update. Hepatology 2010; 49:1335-74.

2. EDHS. Egypt Demographic and Health Survey 2008. Cairo, Egypt: Ministry of Health, ElZanaty F, WaY A and Macro international 2009.

3. Raja NS , Janjua KA. Epidemiology of hepatitis C virus infection in Pakistan. J Microbiol Immunol Infect 2008, 41: 4-8.

4. Giannini E, Risso D, Botta F, Chiarbonello B, Fasoli A, Malfatti F, et al. Validity and clinical utility of the aspartate amino transferase alanine aminotransferase ratio in assessing disease severity and prognosis in patient with hepatitis C virus-related chronic liver disease. Arch Intern Med 2003; 163: 218-24.

5. Fontana RJ , Lok AS. Non- invasive monitoring of patients with chronic hepatitis C. Hepatology 2002; 36: $557-564$.

6. Ahmad W, Ijaz B, Javed FT, Jahan S, Shahid I, and Khan FM, Hassan S . HCV genotype distribution and possible transmission risks in Lahore, Pakistan. World J Gastroenterology 2010 ; 16:4321-4328.

7. Silva RG Jr, Fakhouri R, Nascimento TV, Santos IM, Barbosa LM . Aspartate aminotransferase-toPlatelet ration index for fibrosis and cirrhosis prediction in chronic hepatitis C patients. Braz $J$ Infect Dis 2008, 12:15-19.

8. Ahmad W, Ijaz B, Javed FT, Gull S, Kausar H, Sarwar MT, Asad S et al. A comparison of four fibrosis indexes in chronic HCV: Development of new fibrosis-cirrhosis index (FCI). $B M C$ Gastroenterology 2011, 11:44.

9. Cross TJ, Rizzi P, Berry PA, Bruce M, Portmann B, Harrison PM. Assay (Versant HCV RNA 3.0) for RNA detection and quantification. J Clin Microbiol 2009; 46:3880-3891.
10. Liu T, Wang X, Karsdal MA, Leeming DJ and Genovese F . Molecular Serum Markers of Liver Fibrosis. Liver Research Center 2012; 105-117.

11. Wai CT, Greenson JK, FontanaRJ, Kalbfleisch JD, Marrero JA, Conje evaram HS, et al. A simple noninvasive index can predict both significant fibrosis and cirrhosis in patients with chronic hepatitis C. Hepatology. 2003; 38(2):51826.

12. Vallet-Pichard A, Mallet V, Nalpas B, Verkarre V, Nalpas A, Dhalluin- Venier V, et al. FIB-4: an inexpensive and accurate marker of fibrosis in $\mathrm{HCV}$ infection. Comparison with liver biopsy and fibrotest. Hepatology. 2007; 46(1):32-6.

13. Bedossa P , Poynard T . For the METAVIR Cooperative Group: An algorithm for the grading of activity in chronic hepatitis C. Hepatology 1996 24:289-293.

14. Avunduk C . Percutaneous Liver Biopsy; Manual of Gastroenterology; Diagnosis and Therapy. $3^{\text {rd }}$ edition. Lippincott Williams and Wilkins, Philadelphia, USA Lww.com 2002; 7:27-31.

15. Sherlock S , Dooley J . Anatomy and function (1): 1-16; Biopsy of the liver (3): 37-44 and Hepatic cirrhosis (21): 365-377. In Diseases of the liver and Biliary system "11th Edition", Blackweel Sc. Publ., Oxford London, Edinburgh.2002

16. Bedossa P, Poynard T. An algorithm for the grading of activity in chronichepatitis $\mathrm{C}$. The METAVIR Cooperative Study Group. Hepatology. 1996;24(2):289-93.

17. Saudy N, Elghannam DM, Farag R, Abd ElMaksoud M, El-Hussiny MA, Mohamed EM, et al. Study of some Fibrosis Indices in genotype $4 \mathrm{HCV}$ Infected Egyptian Patients. Life Sci J 2012; 9(1):972-984.

18. Gumusay O, Ozenirler S, Atak A. Diagnostic potential of serum direct markers and noninvasive fibrosis models in patients with chronic hepatitis B. Hepatol Res 2013, 43, 228-37.

19. Yan LB, Zhu X, Bai L, Liang LB, Chen EQ, Du LY et al.Impact of mild to moderate elevations of alanine aminotransferase on liverstiffness measurement in chronic hepatitis B patients during antiviral therapy.Hepatol Res. 2013 ;43(2):185-91.

20. Adam LA . Biomarkers of liver fibrosis. $J$ Gastroenterol Hepatol 2011; 20:802-9.

21. Attallah AM, Abdallah SO, Attallah AA, Omran MM, Farid K, Nasif WA et al.Diagnostic value of fibronectin discriminant score for predicting liver fibrosis stages in chronic hepatitis $\mathrm{C}$ virus patients. Annals of hepatology 2013;47, 12 (1): 44-53. 
22. Attallah AA, Abdallah SO, Omran MM, Farid K, Shaker YM . Assessment of Hepatic Fibrosis Stages in Hepatitis C Virus Infected Patients Using Biomarkers in The Blood. Journal of American Science 2011; 7(12):799-805.

23. Parsian H, Nouri M, Rahimipour A, Somi MH , Qujeq D . Comparison of Five Liver Fibrosis Indexes with Serum Levels of Laminin and $\mathrm{N}$ Terminal Peptide of Procollagen Type III in Chronic Hepatitis Patients, Liver Biopsy, Dr Hirokazu Takahashi (Ed.) 2011.

24. Poynard T, Bedossa P, Opolon P .Natural history of liver fibrosis progression in patients with chronic hepatitis C. The OBSVIRC, METAVIR, CLINIVIR and DOSVIRC groups. Lancet 1997; 349:825-832.
25. Vallet-Pichard A, Mallet V, Nalpas B, Verkarre V, Nalpas A, Dhalluin- Venier V, et al., FIB-4: an inexpensive and accurate marker of fibrosis in $\mathrm{HCV}$ infection. Comparison with liver biopsy and fibrotest. Hepatology. 2007; 46(1):32-6.

Peer reviewer: Rashed Hasan ,Professor of Tropical Medicine and Hepatogastroenterology, Faculty of Medicine, Zagazig University, Egypt. Editor: Tarik Zaher, Professor of Tropical Medicine and Hepatogastroenterology, Faculty of Medicine, Zagazig University, Egypt 